Review article

\title{
Duration of untreated illness as a key to early intervention in schizophrenia: A review
}

\author{
Andrea Murru (MD, PhD) $)^{\mathrm{a}, *}$, Bernardo Carpiniello ${ }^{\mathrm{b}}$ \\ a Bipolar Disorders Unit, Institute of Neuroscience, Hospital Clínic, University of Barcelona, IDIBAPS, CIBERSAM, Barcelona, Catalonia, Spain \\ ${ }^{\mathrm{b}}$ Department of Public Health, Clinical and Molecular Medicine, University of Cagliari, Cagliari, Italy
}

\section{H I G H L I G H T S}

- DUI and DUP are clinical, multidimensional constructs that negatively impact SCZ in the short- and long-term: the shorter the DUP, the better the course of illness.

- Attention must be paid in high-risk populations and patients with subsyndromic psychotic experiences in order to exert a timely intervention.

- Negative symptoms seem related to longer DUP. Negative symptoms are hard to detect, contributing to the delay in diagnosis and intervention.

- Evidence on structural or neurocognitive correlates of DUP is not conclusive. Patients with a longer DUP appear to have worse functional outcomes.

\section{A R T I C L E I N F O}

\section{Article history:}

Received 15 February 2016

Received in revised form 5 September 2016

Accepted 2 October 2016

Available online $\mathrm{xxx}$

\section{Keywords:}

Duration of untreated illness

Duration of untreated psychosis

Schizophrenia

First-episode

Prediction of outcome

Early interventions

\begin{abstract}
A B S T R A C T
The first psychotic episode is classically viewed as a critical period which management is important in determining the long-term outcome of the schizophrenia (SCZ). For this reason, the duration of untreated illness (DUI), defined as the interval between the onset of the psychiatric disorder and the administration of the first pharmacological treatment, is a clinical variable that has been increasingly investigated due to its potentially modifiable nature and its value as a predictor of outcome.

DUI is poorly applicable and highly unreliable in psychosis. The present critical review examines the impact of DUI and its more operative definition of "duration of untreated psychosis" (DUP) in the course and outcome of SCZ, focusing on its epidemiologic, clinical, prognostic factors. Length of DUP has been identified as positively related to a worst treatment response, symptom control and overall functional outcome in SCZ. Negative symptoms appear to be prominently related to longer DUP. Neuroimaging correlates of DUP have not been clearly outlined: few of the studies considering first-episode patients and DUP showed structural abnormalities. A low proportion of significant associations were found mostly in cerebellum and occipital lobe of patients with longer DUP. Also, evidence of an inverse correlation between cognitive alterations and DUP is not conclusive.

DUI and DUP are multidimensional constructs that imply both intrinsic, illness related (e.g. subtle symptoms at onset) and extrinsic factors (e.g. access to mental health services), so that from its study sprouted in the last decades First-Episode Units, aimed at providing secondary prevention in SCZ such as providing a timely diagnosis and treatment to patients experiencing their first psychotic episode. Early intervention seems to ensure a shortened DUP, especially for people presenting with brief limited intermittent psychotic symptoms, and, ultimately, ensure a more favorable prognosis for patients affected by SCZ.
\end{abstract}

(c) 2016 Elsevier Ireland Ltd. All rights reserved.

\section{Contents}

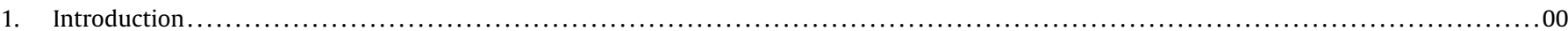

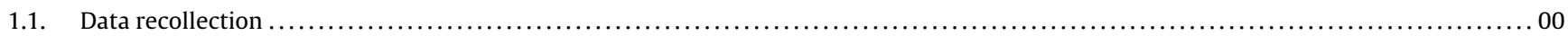

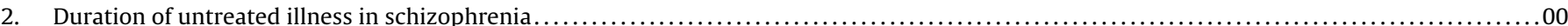

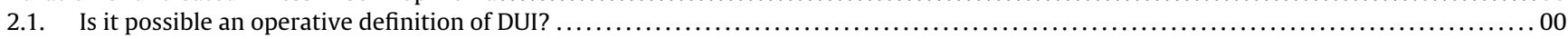

\footnotetext{
* Corresponding author at: Bipolar Disorders Unit, IDIBAPS CIBERSAM, Hospital Clínic, C/Villaroel 170, escalera 12 planta 0, 08036, Barcelona (ES), Spain.

E-mail address: amurru@clinic.ub.es (A. Murru).
} 


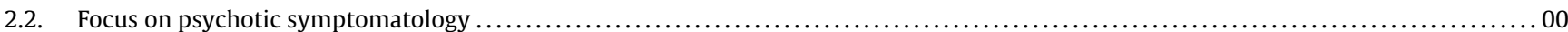

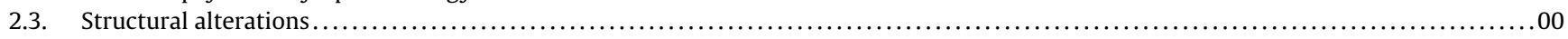

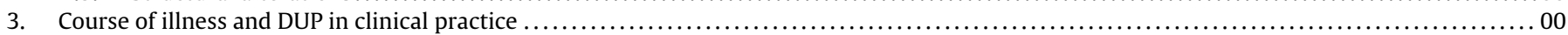

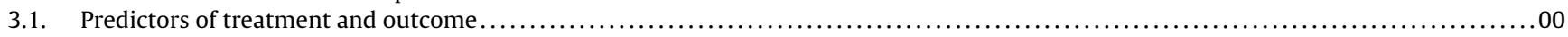

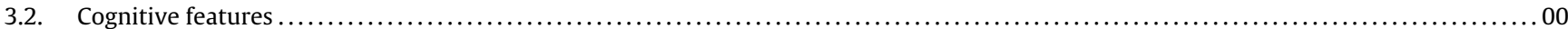

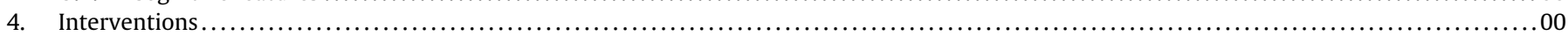

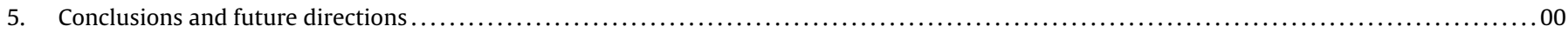

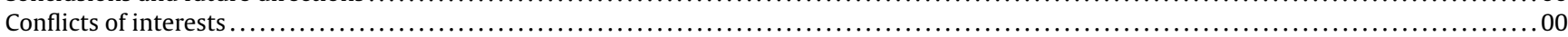

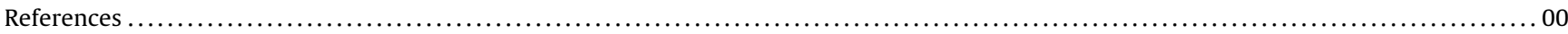

\section{Introduction}

The diagnosis of schizophrenia (SCZ) involves a constellation of cognitive, behavioral and emotional signs and symptoms associated with impaired occupational or social functioning [1]. SCZ is among the most prevalent and disabling mental disorders, responsible for severe functional impairment affecting patients and related caregivers and the significant, increasing costs for the entire community [2]. In particular, the total costs for SCZ seem to be mainly determined by indirect costs such as sick days, unemployment, incomplete education, long-term disability, and suicide attempts $[3,4]$.

The facts that SCZ generally begins in late adolescence/early adulthood, that it often remains untreated for long time before being recognized and treated, and that it frequently shows a chronic, recurrent and disabling course dramatically impact on the relational and functional life of patients and care-givers [5]. For this reason, the first episode of psychosis, considered as early stage SCZ, is classically viewed as a critical period, so that its management is important in determining the long-term outcome of the illness [6]. Unluckily, the extent to which a person with a first episode of psychosis is granted a proper treatment is not homogenous $[7,8]$.

More than $70 \%$ of subjects with mental illness do not receive any treatment for their disorders [9]. Possible factors related to missing/delayed therapy might be represented by poor awareness about psychiatric symptoms and disorders, lack of information about how to access to psychiatric services and treatments and presence of stigma and prejudice toward people with mental illness [10].

Duration of Untreated Illness (DUI) is defined as the time from the emergence of the first psychiatric symptom to initiation of adequate drug treatment. In SCZ it is distinguished from Duration of Untreated Psychosis (DUP), which presents the same endpoint but begins from manifestation of the first psychotic symptom. DUI is a complex clinical concept encompassing both extrinsic factors, such as the mental health laws locally endorsed (i.e. needing dangerousness for involuntary treatment), and intrinsic, illness-related factors $[11,12]$.

From an epidemiologic perspective, large sample studies in SCZ found mean values of DUP ranging from 8 to 48 weeks, whereas higher DUI values, comprised between 3 and 8 years, on average, were reported for mood disorders and anxiety disorders [9,13-17] Although the applicability of DUI may vary according to different disorders and their intrinsic characteristics, studies have shown that subgroups of patients could be identified and subsequently benefit from interventions aimed at reducing DUI in anxiety disorders, unipolar mood disorders and bipolar disorders [14,18,19].

In the case of SCZ, the development of Psychotic First-Episode Units and the study of First-Episode cohorts, followed an increased awareness on the implications of DUP and also allowed for a better understanding of the latency of diagnosis/treatment in psychosis [20]. These interventions sprouted from earlier observations that where deterioration occurs in SCZ, it does so aggressively in the first 2-3 years, and that critical psychosocial influences, including family and psychological reactions to psychosis and psychiatric ser- vices, develop during this period [6]. For these reasons, the early phase of psychosis presents important opportunities for primary and secondary prevention.

In this selective review, we aim at summarizing the current knowledge on duration of untreated illness and psychosis in schizophrenia. Critical, clinical factors related to DUI and DUP will be also presented, as well as implications for treatment management.

\subsection{Data recollection}

Studies published in English on clinical aspects related to DUI and DUP in schizophrenia were reviewed. Electronic library and web-based searches were performed (MEDLINE, PubMED and EMBASE) to identify studies of interest. The literature search was carried out combining the terms "schizophrenia", "psychosis", "DUI" "DUP", "duration of untreated illness/psychosis with "clinical"”, “treatment", “early interventions".

\section{Duration of untreated illness in schizophrenia}

\subsection{Is it possible an operative definition of DUI?}

Solid conclusions on the impact of DUI obviously depend on clear definition of temporal onset and endpoint of DUI. Unfortunately, the very concept of "onset" of illness may be debated, even when referring to untreated psychosis. This heterogeneity may partially account for the different estimates of DUI reported in scientific literature [21].

It is worthwhile emphasizing that another important factor contributing to a longer DUI - particularly in its components related to the age at first pharmacological treatment - may be caused by local factors such as different accessibility to mental health services across countries. Service availability, or lack of, influences the access and subsequent detection of psychiatric conditions. In this sense, DUI may be seen as an indirect measure of the effectiveness of early detection strategies and facilities [22].

The majority of research efforts in the field of early identification and prevention made use of the presence of subclinical psychotic experiences [23] to predict transition to full-blown SCZ. When studied, subclinical psychotic experiences showed very high lifetime prevalence [24-26]. Nonetheless, it should be taken into account that the prognosis of subclinical psychosis also depends on associated features, such as the intensity of subclinical psychosis, degree of associated distress, tendency to experience negative emotions (neuroticism), comorbid depression, and coping [27].

The operationalization of DUI poses as a difficult and highly unreliable task, and most of the studies on psychosis focus on the more operative concept of DUP. Definitions of DUP used in most of the studies on the topic did not address the frequency or severity of psychotic symptoms prior to treatment, but have only monodimensionally measured duration [28]. A problem with the DUP construct is that it assumes an interval in which the psychosis is persistent since the onset $[29,30]$. On the contrary, psychoses of the same gen- 
eral duration, yielding an equivalent measure of DUP, may be quite different in terms of the overall 'dose' of psychosis present before the initiation of treatment [31]. Thus, a potential limitation of the DUP construct as it is currently defined and measured is that it fails to quantify untreated psychosis beyond the simple time interval.

Another element to consider is that, despite having a demonstrated reliability, the endpoint of both DUI and DUP may be criticized as being too simplistic, as, for instance, it does not take into account adherence to pharmacological treatment or the assumption of sub-optimal doses [32].

\subsection{Focus on psychotic symptomatology}

Many studies on the wide topic of DUI in SCZ actually focus on DUP, which is an easier clinical concept to detect and assess,and operationalize the onset of DUP specifically with the emergence of positive symptoms, often hallucinations and delusions. Despite being more precise than DUI, DUP still appears to be a heterogeneous concept. This is especially true considering how symptoms thresholds may be hard to assess retrospectively. DUP measurement seems more reliable when severity thresholds are used, like anchors from an assessment instrument (e.g. the Positive and Negative Syndrome Scale) to set thresholds for positive symptoms included in the operationalization of onset $[7,33]$.

Relying on a uniform definition of DUP may obfuscate important relationships between DUP and clinical variables. For instance, untreated hallucinations and untreated delusions have been shown to bear differential effects, with the former predicting better insight and the latter predicting poorer clinical features such as general symptoms or global functioning [31].

Data from the large CATIE study showed that prominent negative symptoms are present in $40 \%$ of participants with schizophrenia [34]. Moreover, a higher burden of negative symptoms is a consistent predictor of negative short-term [35] and long-term treatment response and functional outcome [36,37]. Deficits are present during all phases of the illness, including first episode SCZ [38,39]. Moreover, some cognitive decline may occur in the early prodromal illness period, until 3-5 years of illness [39]. Not unpredictably, despite the difficulty in directly assessing negative symptoms in DUP, this dimension has shown a clear relation to prolonged duration of untreated psychosis [40].

Despite decades of research on the relevance of negative and cognitive symptoms for functional outcomes in patients with schizophrenia, these elements represent extremely difficult symptom dimensions to consider for early detection [41]. So, the problem of latency in the detection of these symptoms domains should be taken into account due to the burden they represent in the management and functional outcome of SCZ.

Several structured instruments that have been developed for the measurement of DUP and other early course features have been proposed and used [42].

- The Royal Park Multidiagnostic Instrument for Psychosis (RPMIP) is an interview typically conducted on two separate occasions within the same acute episode, and it uses multiple sources of information to characterize a number of features, from onset until termination of psychotic episodes related to SCZ and other psychotic disorders $[43,44]$.

- The Comprehensive Assessment of Symptoms and History (CASH) is a structured interview for SCZ and affective disorders that assesses premorbid functioning, current and past symptoms, treatment, course of illness, sociodemographic variables [45]. It also rates global severity in particular domains (e.g. hallucinations, delusions severity).

- The Interview for the Retrospective Assessment of the Onset of Schizophrenia (IRAOS) is a semi-structured interview aimed at assessing onset of signs/symptoms as well as the temporal sequence of these events [46]. The IRAOS can be administered to both patients and informants, and data from medical charts and clinicians also are included. The onset, course and termination of all psychiatric episodes since the age of 12 years are recorded [46].

- The Symptom Onset in Schizophrenia Inventory (SOS) includes an interview guide and a rating scale to characterize severity and onset date of 15 prodromal and four psychotic symptoms, estimating both the onset of prodromal and syndromic psychosis [47].

- The Circumstances of Onset or Relapse Schedule (CORS) is a semi-structured interview administered at the start of psychiatric treatment and aimed at assessing the patient's status and willingness to engage in treatment, the circumstances that prompted the current treatment as well as demographic data and a medical history [48].

- The Nottingham Onset Schedule (NOS) was designed specifically to assess early psychosis and to aid in identifying time-points for measuring DUP [49].

Some intrinsic methodological aspects of DUP have to be kept in mind. First, DUP is nearly always assessed retrospectively, so that it may be affected by recall bias. Second, recollection of onset data may be further hampered by acute psychotic symptoms, conceptual disorganization and cognitive impairments present in the patient at the time of assessment, during an acute episode [42]. Patients' cooperativeness may be also hampered by acute symptoms. For this reason a consensus evaluation was proposed, similarly to other difficult assessment such as adherence to treatment, in order to combine different sources of information [42,50]

\subsection{Structural alterations}

It has been hypothesized that DUP is not a causal factor for poor outcome, but rather a marker for a more severe manifestation of SCZ [51]. As such, severe cases would develop in a manner that would lead to delayed detection and initiation of treatment. This is consistent with the poorer clinical outcomes shown at both short- and long-term follow-up by patients with an insidious onset of SCZ [52]. It is also possible that the relationship between DUP and outcome is mediated by social support, so that an extended DUP compromises patients' social resources, with negative implications for prognosis [53].

Alternatively, periods of untreated psychosis may be 'biologically toxic' to the brain. This neurotoxicity would occur via several mechanisms, including glutamatergic excitotoxicity, elevated dopamine levels, and persistent catecholaminergic activity [54-57]. Furthermore, prolonged stress resulting from DUP may activate the hypothalamic-pituitary-adrenal axis, leading to greater glucocorticoid secretion which, in turn, may contribute to neuronal damage [58].

A recent meta-analysis including 48 studies aimed at assessing a possible relation between DUP and brain structural alterations detected with structural neuroimaging [59]. The neuroimaging techniques used by the studies were computed tomography, magnetic resonance imaging, MRI with voxel-based morphometry, and diffusion tensor imaging. Less than one-fifth of the studies found an association between DUP and brain structure in first-episode or treatment naïve patients, showing some evidence of a clustering of significant associations in brain regions considered important for psychosis, but with low proportion of significant associations, inconsistent across studies. More in details, the structures found to be correlated with DUP were clustered in the cerebellum (50\% of examined structures statistically significant), occipital lobe (33\%), temporal lobe (14\%), limbic system (14\%), and other regions (60\%) 
[59]. Globally, conclusions on the possible relation between DUP and brain structural alterations could not be drawn, as most of the studies included small samples and other important methodological limitations.

A more recent study, not included in the previous meta-analysis, was conducted using multi-channel near-infrared spectroscopy, a recently developed functional neuroimaging technology allowing non-invasive hemodynamic measurement of neural activity in the frontotemporal regions [60]. Patients in the sample, consisting of $62 \mathrm{SCZ}$ patients divided into short treatment ( $\leq 6$ months, $n=33$ ) or long treatment ( $>6$ months, $n=29$ ), performed a verbal fluency task. Significant associations between a longer DUP and decreased cortical activity approximately at the left inferior frontal, left middle frontal, left postcentral, right precentral, bilateral superior temporal, and bilateral middle temporal gyruses were found, whereas no associations between DUP and brain cortical activity were observed in the short treatment group [60].

\section{Course of illness and DUP in clinical practice}

\subsection{Predictors of treatment and outcome}

DUP seems to exert an effect on response to pharmacological SCZ treatments. Longer DUP seems associated to a worse response to treatment [61]. In the meta-analysis by Perkins and cols. [62] shorter DUP was associated with greater response to antipsychotic treatment, as measured by severity of global psychopathology, positive symptoms, negative symptoms, and functional outcomes. Unfortunately, due to differences in the methods of analysis of the variable "response to treatment" across the different studies included, meta-analytic techniques were not used to combine the results.

The mechanism underlying the fact that DUP could affect treatment response is not clear. DUP most probably affects treatment in a way that might confound the association between DUP and outcomes in SCZ. For instance, some confounders, such as temperament and other personal characteristics, may simultaneously affect DUP and treatment adherence [63]. Indeed, personality domains should be taken into account in order to better understand the phenomenology of early-course psychotic disorders as neuroticism seems positively related to DUP, whilst extraversion, agreeableness, and conscientiousness negatively correlate with DUP [64]. Interestingly, attachment security, DUP and insight were observed to predict recovery from negative symptoms at 12 months in SCZ patients, possibly because attachment security is characterized by openness to seeking help [65].

The correlation between long DUP and poor outcome in the first years of illness has been systematically shown [20,62]. A longer DUP has been associated with poorer functioning and quality of life as well as increased symptoms, including positive psychotic symptoms, particularly for patients with a deterioration in premorbid social functioning $[20,66]$. It is possible that long DUP can reflect characteristics of the psychosis itself rather than a consequence of delay in treatment [67].

In naturalistic studies, a prolonged DUP appears to be linked to poorer outcomes in terms of quality of life, social functioning, and cognitive skills, especially among patients with an insidious onset [68]. Even after more than 4, 8 and 12 years of follow-up, shorter DUP was associated with decreased severity of positive and negative symptoms and greater remission rates, as well as overall functioning and quality of life $[32,69,70]$. Notably, these associations were independent of potential confounding variables such as age, gender, diagnosis, premorbid adjustment, substance misuse and years spent in education, arguing against the notion that DUP may be a proxy for other factors [71].
An association between DUP and negative symptoms at initial treatment contact has been described [31]. However, the direction of this relation is not clear. It does not automatically mean that the symptom dimension actively acts on DUP, as it is likely that negative symptoms at onset, along with premorbid dysfunction and a subtle functional decline, could prevent active help seeking.

A retrospective study on a sample of 88 patients followed for an average period of 25 years associated shorter DUP to a more favorable course of illness in SCZ, measured with direct indicators such as number of hospitalizations, recurrences and severity/functional assessment with the GAF scale [16]. Patients who engage with prodromal services, with a shorter DUP, seem less likely to have been admitted to hospital and to have required compulsory treatment when compared with patients who did not present to services until the first episode of psychosis [72].

Data from several meta-analyses converge on the predictive value of untreated psychotic symptoms on the clinical and functional outcomes among psychotic first-episode patients. A longer DUP seems definitely associated with reduced symptomatic remission, an impaired level of functioning and, predictably, with a poorer quality of life $[20,62,73]$.

Coherently, a recent meta-analysis investigating the possible relation of DUP and clinical, functional and social outcomes in SCZ, [74] found a significant association between long DUP and poor general symptomatic outcome, more severe positive and negative symptoms and failure to achieve remission, as well as decreased social functioning and global outcome, but no significant correlation between DUP and employment, quality of life or hospital treatment [74].

The possible association of family history of psychosis and DUI and DUP has also been studied, with inconclusive results. DUP has been found to be longer in patients with a family history of psychosis [75] but also shorter [76]. In another study, a family history of psychosis was associated with a longer DUP, but not related to the DUI [77]. It is possible that particular cultural and factors may be responsible for explaining the discrepancies between these studies, especially with respect to culturally-specific treatment seeking behaviors that may delay onset of treatment, even if the extent to which this may happen is also debated [78].

\subsection{Cognitive features}

Cognitive impairment is a core feature of psychosis, and most patients suffering from psychosis display neuropsychological deficits long before symptoms onset and similar in magnitude to those observed across different psychiatric disorders [79-82]. Cognitive deficits in first-episode SCZ patients involve several domains (i.e. attention, memory, executive functions and psychomotor speed), showing performances ranging from 0.5 to 1.5 standard deviations below average values $[38,83,84]$.

A possible role of DUP in the cognitive performance of firstepisode SCZ patients is in agreement with the notion that cognitive functioning in first episodes is not a static phenomenon, and slight to moderate improvements occur in the first months after starting antipsychotic drug treatment [20]. Nonetheless, evidence on this theoretic assumption is not conclusive at best.

A 6-month study conducted on 77 drug-naïve, first-episode SCZ patients showed that those with a short DUP with negative or positive symptoms outperformed patients with a long DUP on memory tasks and a pre-attentional visual task but not on measures of verbal fluency, attention, reaction time, visual processing and executive functions [85]. In a prospective 3-years follow-up study conducted on a sample of 99 first-episode Chinese patients, DUP exerted differential effects on various cognitive domains, especially visual and verbal memory deficits, even after adjustment for potential counfounding variables [86]. 
Table 1

Correlates of the different facets of DUP in SCZ.

\begin{tabular}{|c|c|c|}
\hline $\begin{array}{l}\text { DUP Symptom } \\
\text { Dimensions }\end{array}$ & & Correlates \\
\hline \multirow[t]{2}{*}{ Positive } & Hallucinations & Better insight \\
\hline & Delusions & Worse general symptom/functioning \\
\hline Negative & & Negative/poor response to treatment \\
\hline \multirow[t]{2}{*}{ Cognitive } & & Doubtful. \\
\hline & & $\begin{array}{l}\text { Possible involvement of executive functions/Evidence on no correlations in the long } \\
\text { term }\end{array}$ \\
\hline Functional & & decreased social functioning and global outcome, \\
\hline \multirow[t]{2}{*}{ Structural alterations } & Structural neuroimaging & $\begin{array}{l}\text { Scant, inconstant significant associations (cerebellum }>\text { occipital lobe }>\text { temporal } \\
\text { lobe }>\text { limbic system) }\end{array}$ \\
\hline & Functional neuroimaging & $\begin{array}{l}\downarrow \text { cortical activity in: left inferior and middle frontal gyruses, left postcentral gyrus, } \\
\text { right precentral gyrus, bilateral superior and middle temporal gyruses }\end{array}$ \\
\hline
\end{tabular}

Notes. $\downarrow=$ decreased; DUP $=$ Duration of Untreated Psychosis; SCZ = Schizophrenia. See article text for full description.

The association of shorter DUP with greater improvement in executive functions in first-episode SCZ was also observed in an early-onset (before age 18) sample of 66 first-episode SCZ patients, followed prospectively for 2 years [87]. However, the nature of the association between DUP and executive functions is yet to be understood. It is not clear whether is a causal pathway between longer DUP and poorer outcome or, conversely, whether the relationship between DUP and outcome is a spurious finding, with no direct causal link between them $[87,88]$.

Studies reporting no significant association between DUP and cognitive performance were also published [89-93], and no correlation to worse cognitive performance was found in the large first-episode cohort from the EUFEST Study [94]. DUP was also not associated with cognitive or social deterioration in a sample of 101 Chinese first-episode SCZ patients [95]. Similarly, another study conducted on a sample of 60 first-episode SCZ patients showed no association between DUP and cognitive performance, measured with different operativizations of cognition [96].

The longest follow-up so far on a first-episode cohort was recently presented, showing no relationship between DUP and a neurocognitive composite score created for this 10-years followup of 261 first-episode patients [97]. This finding, however, has to be interpreted in the light of at least three aspects. First, the use of a neurocognitive score may have lost a specific correlation between DUP and some cognitive domain. Second, patients who remit without relapse in the first year had a better neurocognitive course throughout the follow-up period compared both to those with unstable remission and to those with continuous psychosis in the first year, and DUP was accordingly shorter in the stable remission subgroup. Last, the distribution of first and second generation antipsychotics throughout the sample was not controlled, introducing a potential bias. Also, a unidimensional approach to DUP, without differentiation of its underlying psychopathological dimensions, may have failed to allow for a prediction of earlycourse symptomatology and functioning. (Compton 2011).

Taken together, the evidence on the possible, inverse relation between cognitive performance and DUP in SCZ does not seem conclusive.

A summary of the correlates of different components of DUP with clinical, functional and structural outcomes in SCZ is presented in Table 1.

\section{Interventions}

Schizophrenia should not be considered an unavoidably deteriorating illness [98]. For this reason, early intervention could ensure a more favorable prognosis $[99,100]$. Early interventions during the ultra-high-risk and first-episode stages of the illness have increasingly been investigated, especially in terms of cognitive behavioral therapy and antipsychotic medications [101] The overall aim is to provide treatment and secondary prevention to reduce relapse, cope with symptoms, and promote recovery following the initial onset of psychosis [102,103].

Early intervention in psychosis can be defined as comprising three foci or stages: ultra-high risk, first episode, and the recovery or critical period [104]. The concept of screening and prevention in schizophrenia hinges on SCZ somehow manifesting itself before the onset of the disease. Historically, a first line of research on pre-onset SCZ focused on the developmental trajectories of children destined later to develop SCZ, and established that there were small, but detectable, group differences between the pre-SCZ children and their peers in terms of motor, social, and cognitive development [105]. Despite the fact that differences were detectable between pre-SCZ children and their peers as early as 2 years of age, these differences were very small, with the great majority of pre-SCZ children scoring well within the normal range [105]. An "ultrahigh risk" group for early transition to SCZ was identified [106] and esteemed to have a relative risk of $40 \%$ compared to the incident rate of psychotic disorders in the general population [107]. Still, this sub-population bears a high and significant false positive rate of $60-80 \%$, pointing at a low feasibility of systematic screening procedures in the general population [102].

Strategies aimed at universal primary prevention have also been applied. Extensive public information campaign conducted to educate the general population, schools, and health professionals alike on the signs and symptoms associated with SCZ showed that an actual improvement in the detection of high-risk individual is possible [108]. However, its cost-effectiveness may be questionable, and it bears a very high risk for false positives attending to mental health facilities [23].

The first clinical service for individuals potentially prodromal for psychosis (Personal Assessment and Crisis Evaluation Clinic) was set up in 1995 in Melbourne, Australia, on the basis of the ultra-high-risk criteria [109]. Following the Melbourne example, other Early Intervention services followed. These specialized interventions, focusing treatment on high risk states, were associated with lower risk of psychosis at 12 months, and at 24 and 36 months [110,111]. Follow-up data showed that specialized units may contribute reducing significantly DUP. In a Norway-based early-detection area DUP was reduced from a median of 26 weeks to 5 weeks, while the usual-detection area had a median of 16 weeks [112]. Patients from the early detection area also showed fewer positive and negative symptoms at presentation, at 2 years, and at 5 years, and they had fewer negative, cognitive, and depressive symptoms at 2 and 5 years [113]. Early detection of first-episode psychosis appears to increase the chances of milder deficits and superior functioning also after 10 years, so that the timing of inter- 
vention seem to have a predictive outcome over the course of SCZ [114].

A recent meta-analytical investigation of risk stratification across different clinical high risk for psychosis subgroups tested the hypothesis of heterogeneous risk levels in the high risk population [115]. People with brief limited intermittent psychotic symptoms represent a separate risk subgroup compared with the attenuated psychotic symptoms, and should be considered separately in future studies on clinical high risk populations $[111,115]$.

Early intervention programs thus confirm, at least partially, their role for the reduction of DUI and DUP in special, ultra-high risk populations. Actually, new results from a study considering the impact of improvements in diagnostic and treatment algorithms over time in DUP support a role on the progressive reduction of DUP in recent years [10]. To further reduce DUP, better links are needed between primary care, emergency rooms, criminal justice and psychiatric services [116]. Multi-component interventions for first-episode psychosis may be both clinically-beneficial and costeffective [117]. Cognitive-behavioral interventions seem to bear the strongest evidence in preventing a first episode of psychosis [118-120]. Evidence on pharmacological treatments (e.g. antipsychotics, omega-3 fatty acids) do not appear as solid [120].

The diffusion of specialized early Intervention programs also allows for an indirect reduction of DUI and DUP, as earlier studies of pathways to care have found stigma and a lack of knowledge of symptoms and treatment services to be important barriers to help seeking, while support from significant others is considered one of the most important facilitating factors [121].

\section{Conclusions and future directions}

DUI is a clinical concept that recognizes different intrinsic and extrinsic components. When considering the course of SCZ, DUI's more operative definition, DUP, is associated with a worse clinical outcome, highest rates of comorbidities and a negative relation with response to treatments.

The correlation between long DUP and poor long-term in SCZ is small, and it is possible that other factors have a stronger impact in determining illness outcome. Considering this, a direct action on DUP such as the one developed with early interventions may have a positive impact on the long-term outcome of SCZ, so that it should be implemented systematically.

In order to better understand the pretreatment prognostic factors in SCZ, the concept of DUP should evolve beyond the notion of a unidimensional duration measure into a multidimensional construct.

Future research in the field of untreated psychotic disorders should aim at providing a better operative definition of DUP, possibly taking into account the different symptomatic dimensions that constitute the core of clinical alterations in SCZ.

A structured improvement of early detections, such as FirstEpisode Units that allow for a systematic follow-up of high risk individuals (such as SCZ patients' siblings) have improved the detection of psychotic disorders and shortened the DUP. People with brief limited intermittent psychotic symptoms represent a separate, special high risk subgroup and should be carefully monitored. Secondary prevention should be encouraged, as the start of an early treatment allows preventing recurrences and chronicity.

Also, research on novel pharmacological treatments should consider the evaluation of the weight of DUP in the response rates shown by patients in trials, in the light of a coherent progression towards a more stratified and personalized treatment plan for each individual patient.

\section{Conflicts of interests}

AM has served as a consultant, adviser, or speaker for Adamed, AstraZeneca, Bristol-Myers Squibb, Janssen-Cilag, Lundbeck, Otsuka, and Sanofi-Aventis. BC has served as a consultant or speaker for Pfizer Italia, Jannsen-Cilag Italia, Otsuka Italia, Lundebeck Italia.

\section{References}

[1] American Psychiatric Association, DSM-5: Diagnostic and Statistical Manual of Mental Disorders, 5th ed, APA, Washington DC, 2013.

[2] H.A. Whiteford, L. Degenhardt, J. Rehm, A.J. Baxter, A.J. Ferrari, H.E. Erskine, F.J. Charlson, R.E. Norman, A.D. Flaxman, N. Johns, R. Burstein, C.J.L. Murray, T. Vos, Global burden of disease attributable to mental and substance use disorders: findings from the Global Burden of Disease Study 2010, Lancet 382 (November (9904)) (2013) 1575-1586.

[3] H.U. Wittchen, F. Jacobi, J. Rehm, A. Gustavsson, M. Svensson, B. Jönsson, J. Olesen, C. Allgulander, J. Alonso, C. Faravelli, L. Fratiglioni, P. Jennum, R. Lieb, A. Maercker, J. van Os, M. Preisig, L. Salvador-Carulla, R. Simon, H.-C. Steinhausen, The size and burden of mental disorders and other disorders of the brain in Europe 2010, Eur. Neuropsychopharmacol. 21 (September (9)) (2011) 655-679.

[4] H.A. Whiteford, A.J. Ferrari, L. Degenhardt, V. Feigin, T. Vos, The global burden of mental, neurological and substance use disorders: an analysis from the Global Burden of Disease Study 2010, PLoS One 10 (January (2)) (2015) e0116820.

[5] P. Jeppesen, L. Petersen, A. Thorup, M.-B. Abel, J. Øhlenschlaeger, T.Ø. Christensen, G. Krarup, P. Jørgensen, M. Nordentoft, The association between pre-morbid adjustment, duration of untreated psychosis and outcome in first-episode psychosis, Psychol. Med. 38 (August (8)) (2008) 1157-1166.

[6] M. Birchwood, P. Todd, C. Jackson, Early intervention in psychosis. The critical period hypothesis, Br. J. Psychiatry Suppl. 172 (33) (1998) 53-59.

[7] T.K. Larsen, T.H. McGlashan, L.C. Moe, First-episode schizophrenia: I. Early course parameters, Schizophr. Bull. 22 (January (2)) (1996) 241-256.

[8] E.C. Johnstone, J.F. Macmillan, C.D. Frith, D.K. Benn, T.J. Crow, Further investigation of the predictors of outcome following first schizophrenic episodes, Br. J. Psychiatry 157 (August) (1990) 182-189.

[9] B. Dell'Osso, G. Camuri, B. Benatti, M. Buoli, A.C. Altamura, Differences in latency to first pharmacological treatment (duration of untreated illness) in anxiety disorders: a study on patients with panic disorder, generalized anxiety disorder and obsessive-compulsive disorder, Early Interv. Psychiatry 7 (November (4)) (2013) 374-380.

[10] B. Dell'Osso, L. Oldani, G. Camuri, B. Benatti, B. Grancini, C. Arici, L. Cremaschi, M. Palazzo, G. Spagnolin, C. Dobrea, A.C. Altamura, Reduced duration of untreated illness over time in patients with schizophrenia spectrum, mood and anxiety disorders, Psychiatry Clin. Neurosci. (January) (2016).

[11] M.M. Large, O. Nielssen, C.J. Ryan, R. Hayes, Mental health laws that require dangerousness for involuntary admission may delay the initial treatment of schizophrenia, Soc. Psychiatry Psychiatr. Epidemiol. 43 (March (3)) (2008) 251-256.

[12] O.B. Nielssen, M.M. Large, Mental health laws influence the duration of untreated psychosis, Psychiatr. Serv. 66 (November (11)) (2015) 1254.

[13] B. Dell'osso, A.C. Altamura, Duration of untreated psychosis and duration of untreated illness: new vistas, CNS Spectr. 15 (April (4)) (2010) 238-246.

[14] A.C. Altamura, M. Buoli, A. Albano, B. Dell'Osso, Age at onset and latency to treatment (duration of untreated illness) in patients with mood and anxiety disorders: a naturalistic study, Int. Clin. Psychopharmacol. 25 (May (3)) (2010) 172-179.

[15] A. Altamura, B. Dell'Osso, H.A. Berlin, M. Buoli, R. Bassetti, E. Mundo, Duration of untreated illness and suicide in bipolar disorder: a naturalistic study, Eur. Arch. Psychiatry Clin. Neurosci. 260 (August (5)) (2010) 385-391.

[16] D. Primavera, C. Bandecchi, T. Lepori, L. Sanna, E. Nicotra, B. Carpiniello, Does duration of untreated psychosis predict very long term outcome of schizophrenic disorders? Results of a retrospective study, Ann. Gen. Psychiatry 11 (January (1)) (2012) 21.

[17] J.D. Bukh, C. Bock, M. Vinberg, L.V. Kessing, The effect of prolonged duration of untreated depression on antidepressant treatment outcome, J. Affect. Disord. 145 (February (1)) (2013) 42-48.

[18] B. Dell'Osso, L. Cremaschi, C. Palazzo, N. Suardi, G. Spagnolin, G. Camuri, B. Benatti, L. Oldani, C. Dobrea, C. Arici, G. Pace, A. Tiseo, E.S. Nahum, F. Castellano, N. D’Urso, M. Clerici, D. Primavera, B. Carpiniello, A.C. Altamura, Factors characterizing access and latency to first pharmacological treatment in Italian patients with schizophrenia, mood, and anxiety spectrum disorders, Int. Clin. Psychopharmacol. 30 (January (1)) (2015) 29-35

[19] A. Murru, D. Primavera, M. Oliva, M.L. Meloni, E. Vieta, B. Carpiniello, The role of comorbidities in duration of untreated illness for bipolar spectrum disorders, J. Affect. Disord. 188 (December) (2015) 319-323.

[20] M. Marshall, S. Lewis, A. Lockwood, R. Drake, P. Jones, T. Croudace, Association between duration of untreated psychosis and outcome in cohorts of first-episode patients: a systematic review, Arch. Gen. Psychiatry 62 (September (9)) (2005) 975-983. 
[21] B. Dell'Osso, I.D. Glick, D.S. Baldwin, A.C. Altamura, Can long-term outcomes be improved by shortening the duration of untreated illness in psychiatric disorders? A conceptual framework, Psychopathology 46 (January (1)) (2013) 14-21.

[22] S.P. Singh, Outcome measures in early psychosis; relevance of duration of untreated psychosis, Br. J. Psychiatry Suppl. 50 (August) (2007) s58-s63.

[23] J. Van Os, P. Delespaul, Toward a world consensus on prevention of schizophrenia, Dialogues Clin. Neurosci. 7 (January (1)) (2005) 53-67.

[24] K.S. Kendler, T.J. Gallagher, J.M. Abelson, R.C. Kessler, Lifetime prevalence, demographic risk factors, and diagnostic validity of nonaffective psychosis as assessed in a US community sample. The National Comorbidity Survey, Arch. Gen. Psychiatry 53 (November (11)) (1996) 1022-1031.

[25] H. Verdoux, S. Maurice-Tison, B. Gay, J. Van Os, R. Salamon, M.L. Bourgeois, A survey of delusional ideation in primary-care patients, Psychol. Med. 28 (January (1)) (1998) 127-134.

[26] R. Poulton, A. Caspi, T.E. Moffitt, M. Cannon, R. Murray, H. Harrington, Children's self-reported psychotic symptoms and adult schizophreniform disorder: a 15-year longitudinal study, Arch. Gen. Psychiatry 57 (November (11)) (2000) 1053-1058.

[27] M. Bak, I. Myin-Germeys, M. Hanssen, R. Bijl, W. Vollebergh, P. Delespaul, J. van Os, When does experience of psychosis result in a need for care? A prospective general population study, Schizophr. Bull. 29 (January (2)) (2003) 349-358

[28] R.M. Norman, A.K. Malla, Duration of untreated psychosis: a critical examination of the concept and its importance, Psychol. Med. 31 (April (3)) (2001) 381-400

[29] T.J. Craig, E.J. Bromet, S. Fennig, M. Tanenberg-Karant, J. Lavelle, N. Galambos, Is there an association between duration of untreated psychosis and 24-month clinical outcome in a first-admission series? Am. J. Psychiatry 157 (January (1)) (2000) 60-66.

[30] B.-C. Ho, D. Alicata, J. Ward, D.J. Moser, D.S. O'Leary, S. Arndt, N.C. Andreasen, Untreated initial psychosis: relation to cognitive deficits and brain morphology in first-episode schizophrenia, Am. J. Psychiatry 160 (January (1)) (2003) 142-148

[31] M.T. Compton, T.L. Gordon, P.S. Weiss, E.F. Walker, The 'doses' of initial, untreated hallucinations and delusions: a proof-of-concept study of enhanced predictors of first-episode symptomatology and functioning relative to duration of untreated psychosis, J. Clin. Psychiatry 72 (November (11)) (2011) 1487-1493.

[32] M. Hill, N. Crumlish, M. Clarke, P. Whitty, E. Owens, L. Renwick, S. Browne, E.A. Macklin, A. Kinsella, C. Larkin, J.L. Waddington, E. O’Callaghan, Prospective relationship of duration of untreated psychosis to psychopathology and functional outcome over 12 years, Schizophr. Res. 141 (November (2-3)) (2012) 215-221

[33] T.K. Larsen, L.C. Moe, L. Vibe-Hansen, J.O. Johannessen, Premorbid functioning versus duration of untreated psychosis in 1 year outcome in first-episode psychosis, Schizophr. Res. 45 (September (1-2)) (2000) 1-9.

[34] J. Rabinowitz, C.G. Berardo, D. Bugarski-Kirola, S. Marder, Association of prominent positive and prominent negative symptoms and functional health, well-being, healthcare-related quality of life and family burden: a CATIE analysis, Schizophr. Res. 150 (November (2-3)) (2013) 339-342.

[35] C. Nordon, F. Rouillon, J.M. Azorin, C. Barry, M. Urbach, B. Falissard, Trajectories of antipsychotic response in drug-naive schizophrenia patients: results from the 6-month ESPASS follow-up study, Acta Psychiatr. Scand. 129 (February (2)) (2014) 116-125.

[36] S. Verma, M. Subramaniam, E. Abdin, L.Y. Poon, S.A. Chong, Symptomatic and functional remission in patients with first-episode psychosis, Acta Psychiatr. Scand. 126 (October (4)) (2012) 282-289.

[37] G. Fervaha, G. Foussias, O. Agid, G. Remington, Impact of primary negative symptoms on functional outcomes in schizophrenia, Eur. Psychiatry 29 (September (7)) (2014) 449-455.

[38] R.M. Bilder, R.S. Goldman, D. Robinson, G. Reiter, L. Bell, J.A. Bates, E. Pappadopulos, D.F. Willson, J.M. Alvir, M.G. Woerner, S. Geisler, J.M. Kane, J.A. Lieberman, Neuropsychology of first-episode schizophrenia: initial characterization and clinical correlates, Am. J. Psychiatry 157 (April (4)) (2000) 549-559.

[39] E. Bora, R.M. Murray, Meta-analysis of cognitive deficits in ultra-high risk to psychosis and first-episode psychosis: do the cognitive deficits progress over, or after, the onset of psychosis? Schizophr. Bull. 40 (July (4)) (2014) $744-755$.

[40] A. Üçok, C. Ergül, Persistent negative symptoms after first episode schizophrenia: a 2-year follow-up study, Schizophr. Res. 158 (September (1-3)) (2014) 241-246.

[41] M. Carbon, C.U. Correll, Thinking and acting beyond the positive: the role of the cognitive and negative symptoms in schizophrenia, CNS Spectr. 19 (December (1)) (2014), pp. 38-52-7, 53.

[42] M. Compton, T. Carter, E. Bergner, L. Franz, T. Stewart, H. Trotman, T. McGlashan, P. McGorry, Defining, operationalizing and measuring the duration of untreated psychosis: advances, limitations and future directions, Early Interv. Psychiatry 1 (3) (2007) 236-250.

[43] P.D. McGorry, D.L. Copolov, B.S. Singh, Royal park multidiagnostic instrument for psychosis: part I. Rationale and review, Schizophr. Bull. 16 (January (3)) (1990) 501-515.

[44] P.D. McGorry, B.S. Singh, D.L. Copolov, I. Kaplan, C.R. Dossetor, R.J. van Riel, Royal park multidiagnostic instrument for psychosis: part II. Development, reliability, and validity, Schizophr. Bull. 16 (January (3)) (1990) 517-536.
[45] N.C. Andreasen, M. Flaum, S. Arndt, The Comprehensive Assessment of Symptoms and History (CASH). An instrument for assessing diagnosis and psychopathology, Arch. Gen. Psychiatry 49 (August (8)) (1992) 615-623.

[46] H. Häfner, A. Riecher-Rössler, M. Hambrecht, K. Maurer, S. Meissner, A. Schmidtke, B. Fätkenheuer, W. Löffler, W. van der Heiden, IRAOS: an instrument for the assessment of onset and early course of schizophrenia, Schizophr. Res. 6 (March (3)) (1992) 209-223.

[47] D.O. Perkins, J. Leserman, L.F. Jarskog, K. Graham, J. Kazmer, J.A. Lieberman, Characterizing and dating the onset of symptoms in psychotic illness: the Symptom Onset in Schizophrenia (SOS) inventory, Schizophr. Res. 44 (July (1)) (2000) 1-10.

[48] K. Register-Brown, L.E. Hong, Reliability and validity of methods for measuring the duration of untreated psychosis: a quantitative review and meta-analysis, Schizophr Res. 160 (December (1-3) (2014) 20-26.

[49] S.P. Singh, J.E. Cooper, H.L. Fisher, C.J. Tarrant, T. Lloyd, J. Banjo, S. Corfe, P. Jones, Determining the chronology and components of psychosis onset: the Nottingham Onset Schedule (NOS), Schizophr. Res. 80 (December (1)) (2005) 117-130.

[50] D.I. Velligan, P.J. Weiden, M. Sajatovic, J. Scott, D. Carpenter, R. Ross, J.P. Docherty, The expert consensus guideline series: adherence problems in patients with serious and persistent mental illness, J. Clin. Psychiatry 70 (January (4)) (2009), 1-46-8.

[51] T.H. McGlashan, Duration of untreated psychosis in first-episode schizophrenia: marker or determinant of course? Biol. Psychiatry 46 (October (7)) (1999) 899-907.

[52] P. Juola, J. Miettunen, J. Veijola, M. Isohanni, E. Jääskeläinen, Predictors of short- and long-term clinical outcome in schizophrenic psychosis-the Northern Finland 1966 birth cohort study, Eur. Psychiatry 28 (June (5)) (2013) 263-268.

[53] R.M.G. Norman, A.K. Malla, R. Manchanda, R. Harricharan, J. Takhar, S. Northcott, Social support and three-year symptom and admission outcomes for first episode psychosis, Schizophr. Res. 80 (December (2-3)) (2005) 227-234

[54] M.S. Keshavan, G.L. Haas, C.E. Kahn, E. Aguilar, E.L. Dick, N.R. Schooler, J.A. Sweeney, J.W. Pettegrew, Superior temporal gyrus and the course of early schizophrenia: progressive, static, or reversible? J. Psychiatr. Res. 32 (January (3-4)) (1998) 161-167.

[55] B. Crespo-Facorro, R. Roiz-Santiáñez, J.M. Pelayo-Terán, C. González-Blanch, R. Pérez-Iglesias, A. Gutiérrez, E.M. de Lucas, D. Tordesillas, J.L. Vázquez-Barquero, Caudate nucleus volume and its clinical and cognitive correlations in first episode schizophrenia, Schizophr. Res. 91 (March (1-3)) (2007) 87-96.

[56] C. de la Fuente-Sandoval, P. León-Ortiz, R. Favila, S. Stephano, D. Mamo, J. Ramírez-Bermúdez, A. Graff-Guerrero, Higher levels of glutamate in the associative-striatum of subjects with prodromal symptoms of schizophrenia and patients with first-episode psychosis, Neuropsychopharmacology 36 (August (9)) (2011) 1781-1791.

[57] T. Natsubori, H. Inoue, O. Abe, Y. Takano, N. Iwashiro, Y. Aoki, S. Koike, N. Yahata, M. Katsura, W. Gonoi, H. Sasaki, H. Takao, K. Kasai, H. Yamasue, Reduced frontal glutamate + glutamine and $\mathrm{N}$-acetylaspartate levels in patients with chronic schizophrenia but not in those at clinical high risk for psychosis or with first-episode schizophrenia, Schizophr. Bull. 40 (September (5)) (2014) 1128-1139.

[58] A.C. Altamura, W.V. Bobo, H.Y. Meltzer, Factors affecting outcome in schizophrenia and their relevance for psychopharmacological treatment, Int. Clin. Psychopharmacol. 22 (September (5)) (2007) 249-267.

[59] K.K. Anderson, M. Rodrigues, K. Mann, A. Voineskos, B.H. Mulsant, T.P. George, K.J. McKenzie, Minimal evidence that untreated psychosis damages brain structures: a systematic review, Schizophr. Res. 162 (March (1)) (2015) 222-233.

[60] P.-H. Chou, S. Koike, Y. Nishimura, S. Kawasaki, Y. Satomura, A. Kinoshita, R. Takizawa, K. Kasai, Distinct effects of duration of untreated psychosis on brain cortical activities in different treatment phases of schizophrenia: a multi-channel near-infrared spectroscopy study, Prog. Neuropsychopharmacol. Biol. Psychiatry 49 (March) (2014) 63-69.

[61] B. Crespo-Facorro, V.O.-G. de la Foz, R. Ayesa-Arriola, R. Pérez-Iglesias, I. Mata, P. Suarez-Pinilla, R. Tabares-Seisdedos, J.L. Vázquez-Barquero, Prediction of acute clinical response following a first episode of non affective psychosis: results of a cohort of 375 patients from the Spanish PAFIP study, Prog. Neuropsychopharmacol. Biol. Psychiatry 44 (July) (2013) 162-167.

[62] D.O. Perkins, H. Gu, K. Boteva, J.A. Lieberman, Relationship between duration of untreated psychosis and outcome in first-episode schizophrenia: a critical review and meta-analysis, Am. J. Psychiatry 162 (October (10)) (2005) $1785-1804$.

[63] D. Dassa, L. Boyer, M. Benoit, S. Bourcet, P. Raymondet, T. Bottai, Factors associated with medication non-adherence in patients suffering from schizophrenia: a cross-sectional study in a universal coverage health-care system, Aust. N. Z. J. Psychiatry 44 (October (10)) (2010) 921-928.

[64] M.T. Compton, R. Bakeman, Y. Alolayan, P.M. Balducci, F. Bernardini, B. Broussard, A. Crisafio, S. Cristofaro, P. Amar, S. Johnson, C.R. Wan, Personality domains, duration of untreated psychosis, functioning, and symptom severity in first-episode psychosis, Schizophr. Res. 168 (October $(1-2))(2015)$ 113-119.

[65] A.I. Gumley, M. Schwannauer, A. Macbeth, R. Fisher, S. Clark, L. Rattrie, G. Fraser, R. McCabe, A. Blair, K. Davidson, M. Birchwood, Insight, duration of untreated psychosis and attachment in first-episode psychosis: prospective 
study of psychiatric recovery over 12-month follow-up, Br. J. Psychiatry 205 (July (1)) (2014) 60-67.

[66] S. Friis, I. Melle, J.O. Johannessen, J.I. Røssberg, H.E. Barder, J.H. Evensen, U. Haahr, W. Ten Velden Hegelstad, I. Joa, J. Langeveld, T.K. Larsen, S. Opjordsmoen, B.R. Rund, E. Simonsen, P.W. Vaglum, T.H. McGlashan, Early predictors of ten-year course in first-episode psychosis, Psychiatr. Serv. (November) (2015), p. appips201400558.

[67] D.C. Owens, E.C. Johnstone, P. Miller, J.F. Macmillan, T.J. Crow, Duration of untreated illness and outcome in schizophrenia: test of predictions in relation to relapse risk, Br. J. Psychiatry 196 (April (4)) (2010) 296-301.

[68] S. Ito, T. Nemoto, N. Tsujino, N. Ohmuro, K. Matsumoto, H. Matsuoka, K. Tanaka, S. Nishiyama, M. Suzuki, H. Kinoshita, H. Ozawa, H. Fujita, S. Shimodera, T. Kishimoto, T. Hasegawa, M. Mizuno, Differential impacts of duration of untreated psychosis (DUP) on cognitive function in first-episode schizophrenia according to mode of onset, Eur. Psychiatry 30 (October (8)) (2015) 995-1001.

[69] M. Clarke, P. Whitty, S. Browne, O. McTigue, M. Kamali, M. Gervin, A. Kinsella, J.L. Waddington, C. Larkin, E. O'Callaghan, Untreated illness and outcome of psychosis, Br. J. Psychiatry 189 (September) (2006) 235-240.

[70] N. Crumlish, P. Whitty, M. Clarke, S. Browne, M. Kamali, M. Gervin, O. McTigue, A. Kinsella, J.L. Waddington, C. Larkin, E. O'Callaghan, Beyond the critical period: longitudinal study of 8-year outcome in first-episode non-affective psychosis, Br. J. Psychiatry 194 (January (1)) (2009) 18-24.

[71] H. Verdoux, F. Liraud, C. Bergey, F. Assens, F. Abalan, J. van Os, Is the association between duration of untreated psychosis and outcome confounded? A two year follow-up study of first-admitted patients, Schizophr. Res. 49 (April (3)) (2001) 231-241.

[72] L.R. Valmaggia, M. Byrne, F. Day, M.R. Broome, L. Johns, O. Howes, P. Power, S. Badger, P. Fusar-Poli, P.K. McGuire, Duration of untreated psychosis and need for admission in patients who engage with mental health services in the prodromal phase, Br. J. Psychiatry 207 (June (2)) (2015) 130-134.

[73] R.M.G. Norman, S.W. Lewis, M. Marshall, Duration of untreated psychosis and its relationship to clinical outcome, Br. J. Psychiatry 48 (2005) s19-s23.

[74] M. Penttilä, E. Jääskeläinen, N. Hirvonen, M. Isohanni, J. Miettunen, Duration of untreated psychosis as predictor of long-term outcome in schizophrenia: systematic review and meta-analysis, Br. J. Psychiatry 205 (August (2)) (2014) 88-94.

[75] R.M.G. Norman, A.K. Malla, R. Manchanda, Delay in treatment for psychosis: its relation to family history, Soc. Psychiatry Psychiatr. Epidemiol. 42 (June (6)) (2007) 507-512.

[76] E.Y.-H. Chen, E.L.-W. Dunn, M.Y.-K. Miao, W.-S. Yeung, C.-K. Wong, W.-F. Chan, R.Y.-L. Chen, K.-F. Chung, W.-N. Tang, The impact of family experience on the duration of untreated psychosis (DUP) in Hong Kong, Soc. Psychiatry Psychiatr. Epidemiol. 40 (May (5)) (2005) 350-356.

[77] M. Esterberg, M. Compton, Family history of psychosis negatively impacts age at onset, negative symptoms, and duration of untreated illness and psychosis in first-episode psychosis patients, Psychiatry Res. 197 (May (1-2)) (2012) 23-28.

[78] K.K. Anderson, N. Flora, S. Archie, C. Morgan, K. McKenzie, Race, ethnicity, and the duration of untreated psychosis: a systematic review, Soc. Psychiatry Psychiatr. Epidemiol. 49 (July (7)) (2014) 1161-1174.

[79] R.W. Heinrichs, K.K. Zakzanis, Neurocognitive deficit in schizophrenia: a quantitative review of the evidence, Neuropsychology 12 (July (3)) (1998) $426-445$

[80] A. Reichenberg, P.D. Harvey, C.R. Bowie, R. Mojtabai, J. Rabinowitz, R.K. Heaton, E. Bromet, Neuropsychological function and dysfunction in schizophrenia and psychotic affective disorders, Schizophr. Bull. 35 (September (5)) (2009) 1022-1029.

[81] K.E. Lewandowski, S.M. Eack, S.S. Hogarty, D.P. Greenwald, M.S. Keshavan, Is cognitive enhancement therapy equally effective for patients with schizophrenia and schizoaffective disorder? Schizophr. Res. 125 (February $(2-3))(2011) 291-294$

[82] B. Sole, C.M. Bonnin, C. Torrent, A. Martinez-Aran, D. Popovic, R Tabarés-Seisdedos, E. Vieta, Neurocognitive impairment across the bipolar spectrum, CNS Neurosci. Ther. 18 (March (3)) (2012) 194-200.

[83] J. Addington, B.L. Brooks, D. Addington, Cognitive functioning in first episode psychosis: initial presentation, Schizophr. Res. 62 (July (1-2)) (2003) 59-64.

[84] G. Heydebrand, M. Weiser, J. Rabinowitz, A.L. Hoff, L.E. DeLisi, J.G. Csernansky, Correlates of cognitive deficits in first episode schizophrenia, Schizophr. Res. 68 (May (1)) (2004) 1-9.

[85] M.J. Cuesta, E. García de Jalón, M.S. Campos, B. Ibáñez, A.M. Sánchez-Torres, V. Peralta, Duration of untreated negative and positive symptoms of psychosis and cognitive impairment in first episode psychosis, Schizophr. Res. 141 (November (2-3)) (2012) 222-227.

[86] W.C. Chang, C.L.M. Hui, J.Y.M. Tang, G.H.Y. Wong, S.K.W. Chan, E.H.M. Lee, E.Y.H. Chen, Impacts of duration of untreated psychosis on cognition and negative symptoms in first-episode schizophrenia: a 3-year prospective follow-up study, Psychol. Med. 43 (September (9)) (2013) 1883-1893.

[87] D. Fraguas, A. Del Rey-Mejías, C. Moreno, J. Castro-Fornieles, M. Graell, S. Otero, A. Gonzalez-Pinto, D. Moreno, I. Baeza, M. Martínez-Cengotitabengoa, C. Arango, M. Parellada, Duration of untreated psychosis predicts functional and clinical outcome in children and adolescents with first-episode psychosis: a 2-year longitudinal study, Schizophr. Res. 152 (January (1)) (2014) $130-138$
[88] B.R. Rund, Does active psychosis cause neurobiological pathology? A critical review of the neurotoxicity hypothesis, Psychol. Med. 44 (June (8)) (2014) $1577-15590$

[89] L.A. Townsend, R.M.G. Norman, A.K. Malla, A.D. Rychlo, R.R. Ahmed, Changes in cognitive functioning following comprehensive treatment for first episode patients with schizophrenia spectrum disorders, Psychiatry Res. 113 (December (1-2)) (2002) 69-81.

[90] J. Addington, S. Van Mastrigt, D. Addington, Duration of untreated psychosis: impact on 2-year outcome, Psychol. Med. 34 (February (2)) (2004) 277-284.

[91] B.R. Rund, I. Melle, S. Friis, J.O. Johannessen, T.K. Larsen, L.J. Midbøe, S. Opjordsmoen, E. Simonsen, P. Vaglum, T. McGlashan, The course of neurocognitive functioning in first-episode psychosis and its relation to premorbid adjustment, duration of untreated psychosis, and relapse, Schizophr. Res. 91 (March (1-3)) (2007) 132-140.

[92] T.R.E. Barnes, V.C. Leeson, S.H. Mutsatsa, H.C. Watt, S.B. Hutton, E.M. Joyce, Duration of untreated psychosis and social function: 1-year follow-up study of first-episode schizophrenia, Br. J. Psychiatry 193 (September (3)) (2008) 203-209.

[93] T.E. Goldberg, K.E. Burdick, J. McCormack, B. Napolitano, R.C. Patel, S.M. Sevy, R. Goldman, T. Lencz, A.K. Malhotra, J.M. Kane, D.G. Robinson, Lack of an inverse relationship between duration of untreated psychosis and cognitive function in first episode schizophrenia, Schizophr. Res. 107 (February (2-3)) (2009) 262-266.

[94] S. Galderisi, M. Davidson, R.S. Kahn, A. Mucci, H. Boter, M.D. Gheorghe, J.K. Rybakowski, J. Libiger, S. Dollfus, J.J. López-Ibor, J. Peuskens, L.G. Hranov, W.W. Fleischhacker, Correlates of cognitive impairment in first episode schizophrenia: the EUFEST study, Schizophr. Res. 115 (December (2-3)) (2009) 104-114

[95] A. Heeramun-Aubeeluck, N. Liu, F. Fischer, N. Huang, F. Chen, L. He, C. Yang, Y. Luo, Z. Lu, Effect of time and duration of untreated psychosis on cognitive and social functioning in Chinese patients with first-episode schizophrenia: a 1-year study, Nord. J. Psychiatry 69 (May (4)) (2015) 254-261.

[96] C. Rapp, E. Studerus, H. Bugra, J. Aston, C. Tamagni, A. Walter, M. Pflueger, S. Borgwardt, A. Riecher-Rössler, Duration of untreated psychosis and cognitive functioning, Schizophr. Res. 145 (April (1-3)) (2013) 43-49.

[97] B.R. Rund, H.E. Barder, J. Evensen, U. Haahr, W.T.V. Hegelstad, I. Joa, J.O. Johannessen, J. Langeveld, T.K. Larsen, I. Melle, S. Opjordsmoen, J.I. Røssberg, E. Simonsen, K. Sundet, P. Vaglum, T. McGlashan, S. Friis, Neurocognition and duration of psychosis: a 10-year follow-up of first-episode patients, Schizophr. Bull. 42 (January (1)) (2016) 87-95.

[98] R.B. Zipursky, T.J. Reilly, R.M. Murray, The myth of schizophrenia as a progressive brain disease, Schizophr. Bull. 39 (November (6)) (2012) $1363-1372$.

[99] M.R. Stafford, H. Jackson, E. Mayo-Wilson, A.P. Morrison, T. Kendall, Early interventions to prevent psychosis: systematic review and meta-analysis, BMJ 346 (January) (2013) f185.

[100] J. van Os, R.M. Murray, Can we identify and treat 'schizophrenia light' to prevent true psychotic illness? BMJ 346 (January) (2013) f304

[101] P. Liu, A.G. Parker, S.E. Hetrick, P. Callahan, S. de Silva, R. Purcell, An evidence map of interventions across premorbid, ultra-high risk and first episode phases of psychosis, Schizophr. Res. 123 (October (1)) (2010) 37-44.

[102] P.D. McGorry, E. Killackey, A. Yung, Early intervention in psychosis: concepts, evidence and future directions, World Psychiatry 7 (October (3)) (2008) 148-156

[103] D.A. White, L. Luther, K.A. Bonfils, M.P. Salyers, Essential components of early intervention programs for psychosis: available intervention services in the United States, Schizophr. Res. 168 (October (1-2)) (2015) 79-83.

[104] P.D. McGorry, I.B. Hickie, A.R. Yung, C. Pantelis, H.J. Jackson, Clinical staging of psychiatric disorders: a heuristic framework for choosing earlier, safer and more effective interventions, Aust. N. Z. J. Psychiatry 40 (August (8)) (2006) 616-622.

[105] P. Jones, B. Rodgers, R. Murray, M. Marmot, Child development risk factors for adult schizophrenia in the British 1946 birth cohort, Lancet (London, England) 344 (November (8934)) (1994) 1398-1402.

[106] A.R. Yung, L.J. Phillips, H.P. Yuen, S.M. Francey, C.A. McFarlane, M. Hallgren, P.D. McGorry, Psychosis prediction: 12-month follow up of a high-risk ('prodromal') group, Schizophr. Res. 60 (March (1)) (2003) 21-32.

[107] T.D. Cannon, K. Cadenhead, B. Cornblatt, S.W. Woods, J. Addington, E. Walker, L.J. Seidman, D. Perkins, M. Tsuang, T. McGlashan, R. Heinssen, Prediction of psychosis in youth at high clinical risk: a multisite longitudinal study in North America, Arch. Gen. Psychiatry 65 (January (1)) (2008) 28-37.

[108] J.O. Johannessen, T.H. McGlashan, T.K. Larsen, M. Horneland, I. Joa, S. Mardal, R. Kvebaek, S. Friis, I. Melle, S. Opjordsmoen, E. Simonsen, H. Ulrik, P. Vaglum, Early detection strategies for untreated first-episode psychosis, Schizophr. Res. 51 (August (1)) (2001) 39-46.

[109] A.R. Yung, P.D. McGorry, C.A. McFarlane, H.J. Jackson, G.C. Patton, A. Rakkar, Monitoring and care of young people at incipient risk of psychosis, Schizophr. Bull. 22 (January (2)) (1996) 283-303.

[110] A. Preti, M. Cella, Randomized-controlled trials in people at ultra high risk of psychosis: a review of treatment effectiveness, Schizophr. Res. 123 (October (1)) (2010) 30-36.

[111] P. Fusar-Poli, S. Borgwardt, A. Bechdolf, J. Addington, A. Riecher-Rössler, F. Schultze-Lutter, M. Keshavan, S. Wood, S. Ruhrmann, L.J. Seidman, L. Valmaggia, T. Cannon, E. Velthorst, L. De Haan, B. Cornblatt, I. Bonoldi, M. Birchwood, T. McGlashan, W. Carpenter, P. McGorry, J. Klosterkötter, P. 
G Model

NSL-32339; No. of Pages 9

A. Murru, B. Carpiniello / Neuroscience Letters xxx (2016) $x x x-x x x$

9

McGuire, A. Yung, The psychosis high-risk state: a comprehensive state-of-the-art review, JAMA Psychiatry 70 (January (1)) (2013) 107-120.

[112] T.K. Larsen, T.H. McGlashan, J.O. Johannessen, S. Friis, C. Guldberg, U. Haahr, M. Horneland, I. Melle, L.C. Moe, S. Opjordsmoen, E. Simonsen, P. Vaglum, Shortened duration of untreated first episode of psychosis: changes in patient characteristics at treatment, Am. J. Psychiatry 158 (November (11)) (2001) 1917-1919.

[113] I. Melle, T.K. Larsen, U. Haahr, S. Friis, J.O. Johannessen, S. Opjordsmoen, E. Simonsen, B.R. Rund, P. Vaglum, T. McGlashan, Reducing the duration of untreated first-episode psychosis: effects on clinical presentation, Arch. Gen. Psychiatry 61 (February (2)) (2004) 143-150.

[114] W. ten, V. Hegelstad, T.K. Larsen, B. Auestad, J. Evensen, U. Haahr, I. Joa, J.O. Johannesen, J. Langeveld, I. Melle, S. Opjordsmoen, J.I. Rossberg, B.R. Rund, E. Simonsen, K. Sundet, P. Vaglum, S. Friis, T. McGlashan, Long-term follow-up of the TIPS early detection in psychosis study: effects on 10-year outcome, Am. J. Psychiatry 169 (April (4)) (2012) 374-380.

[115] P. Fusar-Poli, M. Cappucciati, S. Borgwardt, S.W. Woods, J. Addington, B. Nelson, D.H. Nieman, D.R. Stahl, G. Rutigliano, A. Riecher-Rössler, A.E. Simon, M. Mizuno, T.Y. Lee, J.S. Kwon, M.M.L. Lam, J. Perez, S. Keri, P. Amminger, S. Metzler, W. Kawohl, W. Rössler, J. Lee, J. Labad, T. Ziermans, S.K. An, C.-C. Liu, K.A. Woodberry, A. Braham, C. Corcoran, P. McGorry, A.R. Yung, P.K. McGuire, Heterogeneity of psychosis risk within individuals at clinical high risk: a meta-analytical stratification, JAMA Psychiatry 73 (December (2)) (2015) 1-8.

[116] K. Bhui, S. Ullrich, J.W. Coid, Which pathways to psychiatric care lead to earlier treatment and a shorter duration of first-episode psychosis? BMC Psychiatry 14 (January) (2014) 72.
[117] N.J.K. Breitborde, E.K. Bell, D. Dawley, C. Woolverton, A. Ceaser, A.C. Waters, S.C. Dawson, A.W. Bismark, A.J. Polsinelli, L. Bartolomeo, J. Simmons, B. Bernstein, P. Harrison-Monroe, The Early Psychosis Intervention Center (EPICENTER): development and six-month outcomes of an American first-episode psychosis clinical service, BMC Psychiatry 15 (January) (2015) 266.

[118] H.K. Ising, J. Lokkerbol, J. Rietdijk, S. Dragt, R.M.C. Klaassen, T. Kraan, N. Boonstra, D.H. Nieman, D.P.G. van den Berg, D.H. Linszen, L. Wunderink, W. Veling, F. Smit, M. van der Gaag, Four-year cost-effectiveness of cognitive behavior therapy for preventing first-episode psychosis: the Dutch early detection intervention evaluation (EDIE-NL) trial, Schizophr. Bull. (June) (2016).

[119] H.K. Ising, F. Smit, W. Veling, J. Rietdijk, S. Dragt, R.M.C. Klaassen, N.S.P. Savelsberg, N. Boonstra, D.H. Nieman, D.H. Linszen, L. Wunderink, M. van der Gaag, Cost-effectiveness of preventing first-episode psychosis in ultra-high-risk subjects: multi-centre randomized controlled trial, Psychol, Med. 45 (May (7)) (2015) 1435-1446.

[120] M. van der Gaag, F. Smit, A. Bechdolf, P. French, D.H. Linszen, A.R. Yung, P. McGorry, P. Cuijpers, Preventing a first episode of psychosis: meta-analysis of randomized controlled prevention trials of 12 month and longer-term follow-ups, Schizophr. Res. 149 (September (1-3)) (2013) 56-62.

[121] S. Tanskanen, N. Morant, M. Hinton, B. Lloyd-Evans, M. Crosby, H. Killaspy, R. Raine, S. Pilling, S. Johnson, Service user and carer experiences of seeking help for a first episode of psychosis: a UK qualitative study, BMC Psychiatry 11 (January) (2011) 157.

Please cite this article in press as: A. Murru, B. Carpiniello, Duration of untreated illness as a key to early intervention in schizophrenia:

A review, Neurosci. Lett. (2016), http://dx.doi.org/10.1016/j.neulet.2016.10.003 